\title{
KREDIT PEMILIKAN RUMAH SYARIAH TANPA BANK: STUDI DI JAWA BARAT
}

\section{Egi Arvian Firmansyah \& Deru R Indika}

Departemen Manajemen dan Bisnis, Fakultas Ekonomi dan Bisnis Universitas Padjadjaran

E-mail: egi.firmansyah@unpad.ac.id

\begin{abstract}
Home mortgage or KPR is deemed as an alternative solution for owning a house in this increasingly difficult era. Home mortgage can be done either through conventional bank, sharia bank or non-bank. According to the our observation, the research on the practice of non-bank mortgage is still relatively scant so that this study is expected to add literature on Islamic Home Financing especially in the Muslim-majority developing country. The result of this research is expected to be a suggestion and input for the property businessman, especially those who are concerned with the aspect of sharia compliance, the banking and society in general.
\end{abstract}

Keywords: Islamic housing, non-bank mortgage, no riba. 


\section{Egi Arvian Firmansyah \\ Deru R Indika}

\section{PENDAHULUAN}

Rumah merupakan salah satu aset yang mungkin paling mahal yang dapat dimiliki oleh seorang manusia selama hidupnya. Usaha untuk memiliki rumah seringkali merupakan upaya paling berat terutama bagi masyarakat yang hidup di perkotaan karena semakin mahalnya harga tanah dan rumah. Untuk mengatasi hambatan ini, skema kredit atau KPR (Kredit Pemilikan Rumah) sering menjadi pilihan banyak masyarakat. Di saat ekonomi yang kurang bergairah, kenaikan harga rumah dan tanah tersebut tidak selalu diiringi dengan kenaikan pendapatan sehingga semakin banyak masyarakat yang kesulitan untuk memiliki rumah. Penelitian ini bertujuan untuk menggali profil para pembeli rumah yang menggunakan skema KPR syariah tanpa bank yang merupakan skema kredit dimana pembeli langsung mencicil kepada pengembang. Dalam penelitian ini, KPR syariah tanpa bank maksudnya adalah KPR syariah tanpa menggunakan intermediasi lembaga keuangan apa pun baik bank maupun non-bank seperti koperasi. Skema KPR syariah tanpa bank ini masih relatif baru namun cukup berkembang di kota-kota di Indonesia. Sejauh pengamatan penulis, penelitian KPR syariah tanpa bank masih relatif baru sehingga penelitian ini diharapkan menambah pengetahuan dan wawasan dalam bidang kevangan syariah dimana penelitian KPR syariah mayoritas menggunakan bank.

Skema KPR syariah dengan perbankan biasanya menggunakan kontrak murabahah (jual beli) dimana bank bertindak sebagai penjual dan konsumen sebagai pembeli. Kontrak lainnya yaitu musyarakah mutanaqisah (MM) yang merupakan turunan antara kemitraan (musyarakah) dan sewa atau ijarah (Smolo \& Hassan, 2011). Contoh dari kontrak MM ini misalnya, konsumen dan bank patungan membeli sebuah rumah dengan proporsi dana $20 \%$ dari konsumen dan $80 \%$ dari bank. Kemudian konsumen membayar cicilan kepada bank yang terdiri dari dua komponen yaitu sewa dan pembelian rumah. Seiring waktu, pembayaran cicilan ini mengakibatkan proporsi kepemilikan (share) konsumen semakin besar dan proporsi kepemilikan bank semakin sedikit sehingga rumah tersebut pada akhirnya dapat dimiliki oleh konsumen.

Berbeda dengan skema KPR menggunakan berbankan yang lazim dilakukan di Indonesia dan di negara lain, KPR syariah tanpa bank muncul sebagai alternatif yang relatif baru bagi para calon pembeli rumah. KPR syariah tanpa bank pada dasarnya kredit dimana para pembeli rumah tidak menggunakan bank dalam praktinya sehingga pembeli rumah langsung membayar cicilan kepada developer. Proses KPR syariah tanpa bank berbeda dengan KPR biasa menggunakan bank. KPR syariah tanpa bank dipercayai dapat lebih memudahkan pelanggan karena pelanggan tidak diharuskan berurusan dengan hal administratif yang sering kali membebani. KPR syariah tanpa bank dianggap memiliki fleksibilitas tinggi karena memiliki berbagai fitur sebagai berikut; tidak ada BI checking, tidak memerlukan slip gaji atau SK sehingga cocok untuk para pengusaha non formal seperti para pedagang, tanpa sita, tanpa denda, dan tanpa riba. Beberapa fitur tersebut menjadi andalan para pengembang yang mereka sampaikan di media promosi seperti website atau media sosial seperti Facebook, grup WhatsApp dan Blackberry messenger.

Seiring berkembangnya KPR syariah tanpa bank di berbagai kota di Indonesia, kami tertarik mempelajari hal ini karena merupakan bidang yang relatif baru. Berdasarkan pengamatan kami, para peneliti di dalam maupun di luar negeri masih belum banyak menyentuh ranah ini. Penelitian kami difokuskan pada pencarian informasi mengenai profil para pembeli rumah dengan skema KPR tanpa bank. Selanjutnya, informasi lain misalnya mengenai alasan para konsumen KPR tanpa bank juga digali untuk memperoleh pemahaman akan preferensi 
mereka. Saran dari para responden terkait praktik KPR syariah tanpa bank berguna untuk pengembangan praktik ini di masa mendatang.

Tulisan ini dibagi kedalam lima bagian dimana bagian pertama ini menggambarkan latar belakang yang menjadi dasar dilakukannya penelitian. Bagian berikutnya menjelaskan beberapa literatur yang berkaitan dengan KPR syariah (Is/amic mortgage) baik menggunakan bank maupun tidak menggunakan bank. Bagian metode mengikuti bagian kedua ini dimana dijelaskan data serta teknik pengumpulan informasi dari sampel penelitian. Bagian berikutnya adalah bagian hasil dan pembahasan yang merupakan inti dari tulisan ini. Terakhir, bagian kesimpulan dan saran disampaikan bagi para peneliti di masa depan yang tertarik mempelajari KPR syariah tanpa bank.

\section{LANDASAN TEORI}

\section{KPR Syariah}

KPR syariah merupakan skema KPR menggunakan transaksi yang sesuai dengan syariah Islam. Di masyarakat, KPR identik dengan perbankan padahal KPR tidak hanya dapat dilakukan dengan menggunakan intermediari perbankan, namun dapat juga menggunakan koperasi atau lembaga keuangan lainnya. KPR syariah pada dasarnya mengikuti prinsip-prinsip bagi hasil dan bagi rugi (risk sharing dan profit sharing) dan penerimaan serta pembayaran bunga atas pinjaman tidak dapat dikatakan sesuai syariah (Bellalah, Rehman, \& Masood, 2013). Dengan demikian, KPR syariah yang umum dilakukan adalah menggunakan perantara perbankan syariah yang menggunakan paling tidak dua kontrak yaitu kontrak jual beli (murabahah) dan kontrak sewa beli (ijarah).

\section{Penelitian KPR Syariah terdahulu}

Menurut pengamatan kami, penelitian mengenai KPR syariah tanpa bank relatif masih sedikit. Adapun studi mengenai hal ini pernah dilakukan oleh Firmansyah namun masih bersifat deskriptif (Firmansyah, 2016). Penelitian tersebut masih merupakan studi literatur dan berupa artikel konseptual sehingga dalam penelitian ini kami mencoba memperluas dan memperdalam cakupan penelitian dengan menggunakan metode survey lapangan. Bedanya penelitian ini dengan penelitian Firmansyah yang dilakukan tahun 2016 adalah penelitian ini telah menggunakan instrumen kuesioner dalam pengumpulan data terutama data primer.

Di negara lain, penelitian KPR syariah tanpa bank juga relatif belum ada. Penelitian mengenai KPR syariah telah dilakukan di berbagai negara namun menggunakan perantara bank, diantaranya (Amin, Rahman, Razak, \& Rizal, 2017) di Malaysia, (Hamid \& Masood, 2011 ) di Pakistan, (Yusof, Bahlous, \& Haniffa, 2016) di Inggris dan (Wulandari, Putri, Kassim, \& Sulung, 2016) di Indonesia. Berdasarkan pengamatan yang kami lakukan, terdapat gap antara penelitian KPR syariah tanpa bank di Indonesia dengan praktiknya yang tengah berlangsung. Praktik KPR syariah tanpa bank telah berkembang di beberapa kota misalnya di Bandung dan sekitarnya, Bogor, Depok, Sukabumi, dan Makassar.

\section{Legalitas KPR Syariah tanpa bank}

Aturan baku mengenai praktik KPR Syariah tanpa bank masih belum ada. Para pelakU transaksi ini berpijak pada hukum Islam bahwa transaksi muamalah itu dapat dilakukan asal suka sama suka dan tidak melanggar aturan yang telah ditetapkan syariah. Atas dasar ini, praktik KPR syariah cukup banyak dilakukan di beberapa kota di Indonesia mesikipun tidak 


\section{Egi Arvian Firmansyah \\ Deru R Indika}

ada aturan baku yang mengaturnya. Namun, keterlibatan notaris dalam transaksi KPR syariah tanpa bank menjadi hal yang sangat penting dan ini dianggap mencukupi aspek legalitas dalam kegiatan transaksi.

Selain itu, kepercayan dan komitmen antar pelaku menjadi kunci utama demi berjalannya transaksi ini. Artinya, developer tidak ingkar janji dan menyerahkan rumah beserta suratsuratnya ketika cicilan telah dilunasi pembeli. Begitu pun dengan pembeli bertekad menjaga rumah dan berupaya untuk melunasi utangnya hingga akhir periode.

\section{Mekanisme KPR Syariah Tanpa Bank}

Skema KPR syariah tanpa bank dianggap lebih sederhana dan lebih fleksibel karena tidak melibatkan intermediari perbankan atau lembaga keuangan lainnya. Pihak ketiga yang dilibatkan dalam transaksi adalah notaris yang berperan melegalkan transaksi secara hukum. Berikut ini mekanisme KPR syariah tanpa bank yang berlangsung di Indonesia:

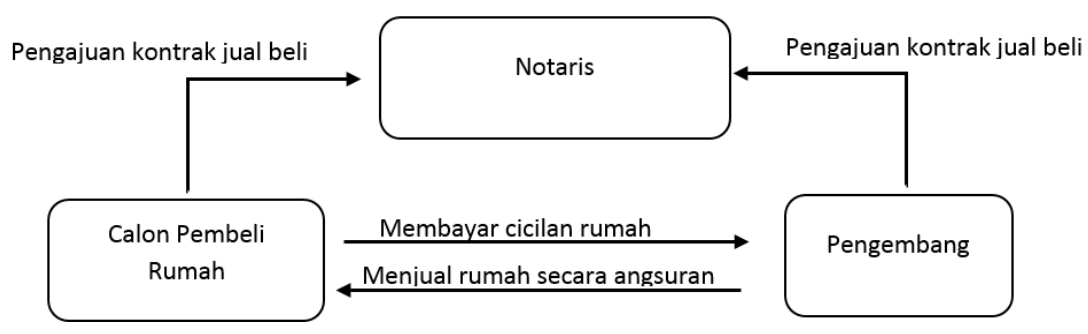

Gambar 1. Skema KPR Syariah Tanpa Bank

Sumber: (Firmansyah, 2016) dengan adaptasi

\section{METODE PENELITIAN}

Penelitian ini menggunakan data sekunder dan data primer. Data sekunder dikumpulkan dengan cara melakukan studi literatur dari berbagai sumber seperti jurnal, laporan, dan website. Data primer dikumpulkan dengan cara penyebaran kuesioner kepada para responden yang ada di kota-kota di Indonesia. Awalnya, sasaran responden adalah mereka para pembeli rumah syariah tanpa bank yang berada di area Bandung Raya (Kota Bandung, Kabupaten Bandung, Kabupaten Bandung Barat, dan Kota Cimahi). Namun, karena keterbatasan jumlah sampel, maka cakupan area penelitian diperluas sehingga sasaran responden yang diwawancarai adalah para pembeli rumah yang menggunakan skema syariah tanpa bank di Jawa Barat. Dengan demikian, para responden dalam penelitian ini selain dari area Bandung Raya juga berasal dari kota Sukabumi dan Purwakarta. Kuesioner yang disebarkan merupakan kuesioner versi daring (online) yaitu menggunakan media Google Form sehingga lebih efisien karena kami dapat hanya membawa telepon genggam saat melakukan wawancara. Adapun jenis pertanyaan yang ditanyakan pada para responden adalah profil, preferensi atau alasan memilih KPR syariah tanpa bank, dan saran untuk pengembangan kredit syariah tanpa bank. Penelitian dilakukan pada tahun 2017 yaitu dari bulan Maret hingga November. 


\section{Jurnal Manajemen Teori dan Terapan \\ Tahun 10. No. 3, Desember 2017}

\section{HASIL DAN PEMBAHASAN}

\section{Profil Responden}

Berdasarkan survey yang telah dilakukan, responden yang berhasil diwawancarai sejumlah 29 responden. Banyak responden yang tidak berhasil diwawancarai karena berbagai alasan, alatas paling banyak diantaranya tidak ingin diganggu. Adapun responden yang berhasil diwawancarai adalah responden dari daerah Sukabumi, Purwakarta, Kabupaten Bandung Barat, dan Kota Bandung. Mayoritas responden berusia antara 25-35 tahun $(58,6 \%)$ atau dikategorikan sebagai keluarga muda. Ada 37,9\% responden berusia 35-50 tahun dan hanya $6,9 \%$ responden yang berusia di bawah 25 tahun. sebanyak $58,6 \%$ responden yang kami wawancarai adalah wanita dan sisanya adalah pria. Hal ini dimungkinkan karena preferensi keluarga responden yang mana wanita atau istri biasanya di rumah dan pria atau suami bekerja. Mayoritas responden $(93,1 \%)$ yang kami wawancarai telah menikah atau telah berkeluarga dengan $40 \%$ responden memiliki satu orang anak, $32 \%$ responden belum atau tidak memiliki anak, 24\% responden memiliki 2 orang anak, dan $4 \%$ responden memiliki 3 orang anak. Dari angka ini jelas bahwa mayoritas responden adalah keluarga kecil atau keluarga muda.

Dilihat dari segi pendidikan, $48,3 \%$ telah bergelar sarjana dan $31 \%$ responden memiliki pendidikan terakhir SLTA. Terdapat $10,3 \%$ responden yang berpendidikan S2 dan $3,4 \%$ responden bergelar \$3. Terdapat pula terdapat 3,4\% responden yang berpendidikan terakhir SLTP dan diploma. Dari data ini, dapat dilihat bahwa mayoritas responden adalah kaum yang cukup berpendidikan.

Profesi yang paling banyak di antara responden adalah pegawai swasta (31\%). Terdapat 24,1\% wiraswasta, 20,7\% Ibu Rumah Tangga dan sisanya ada yang berprofesi sebagai pegawai negeri sipil (PNS), guru, dan karyawan BUMD. Dengan profil profesi tersebut, sebanyak 50\% responden memiliki penghasilan bulanan sebesar 5-8 juta rupiah, 21,4\% berpenghasilan 8-10 juta rupiah, 17,9\% berpenghasilan lebih dari 10 juta rupiah, dan 10,7\% berpenghasilan 3-5 juta rupiah. Dari data penghasilan ini, dapat dikatakan bahwa mayoritas responden adalah kaum menengah (middle class).

\section{Preferensi}

Aspek terpenting bagi responden dalam membeli rumah berbeda-berbeda. Mayoritas responden $(44,8 \%)$ setuju bahwa lingkungan adalah aspek paling penting saat menentukan tempat tinggal. Hal ini mencakup keamanan, ketenangan, dan keramahan para tetangga. Terdapat $31 \%$ responden menjawab bahwa aspek syariah adalah hal terpenting. Hal ini membuat para responden tidak mau mengajukan KPR dengan menggunakan perantara bank atau lembaga keuangan lainnya untuk dapat memiliki sebuah rumah. Ada juga yang menjawab bahwa lokasi adalah hal terpenting (13,8 \%). Walaupun penting, hanya sebanyak $6,9 \%$ responden yang menjawab bahwa kualitas bangunan adalah hal yang terpenting ketika mempertimbangan untuk membeli rumah. Hanya terdapat $3,4 \%$ responden yang menjawab bahwa harga adalah faktor paling penting.

Untuk lebih memverifikasi jawaban-jawaban terkait preferensi nasabah dalam melakukan KPR, kami juga menggali informasi dari responden menggunakan pernyataan dalam skala Likert dimana poin 5 adalah sangat penting dan poin 1 adalah untuk sangat tidak penting. Berikut disajikan tabel mengenai jawaban responden atas pernyataan yang diajukan terkait KPR. 
Tabel 1. Persentase Responden terkait aspek dalam KPR

\begin{tabular}{lc}
\hline \multicolumn{1}{c}{ Aspek } & $\begin{array}{c}\text { Persentase responden } \\
\text { memilih sangat setuju }\end{array}$ \\
\hline Lokasi & $79,3 \%$ \\
Harga & $58,6 \%$ \\
Harga Jual Kembali & $48,2 \%$ \\
Kualitas bangunan & $62,0 \%$ \\
Faktor keamanan & $82,7 \%$ \\
Aspek syariah & $75,8 \%$ \\
Angsuran tetap & $55,1 \%$ \\
Proses cepat & $62,0 \%$ \\
Jangka waktu pembayaran & $31,0 \%$ \\
Iklan \& promo menarik & $20,6 \%$ \\
Kemudahan pelunasan kredit & $55,1 \%$ \\
Rekomendasi teman/ keluarga & $27,5 \%$ \\
Pelayanan yang diberikan & $58,6 \%$ \\
Sistem pembayaran yang mudah diakses & $62,0 \%$ \\
Akad/perjanjian yang jelas & $93,1 \%$ \\
\hline
\end{tabular}

Sumber: Data diolah (2017)

Dari tabel 1, diketahui bahwa tiga aspek paling penting di mata responden ketika memutuskan untuk memiliki rumah adalah akad/perjanjian yang jelas, faktor keamanan, dan lokasi. Ketiga faktor ini dapat fokus para pemasar atau pengembang yang menjual rumah menggunakan skema tanpa bank.

Terkait praktik KPR saat ini dengan menggunakan perantara perbankan syariah, mayoritas responden $(55,2 \%)$ berpendapat bahwa praktik tersebut tidak atau belum sesuai syariah sehingga mereka tidak menempuh jalan ini untuk dapat memiliki rumah. Hal ini membuat para responden memilih praktik KPR syariah tanpa bank apalagi perbankan konvensional yang sudah jelas dianggap riba atau tidak sesuai dengan ajaran Islam. Alasan berikutnya untuk memilih skema KPR syariah tanpa bank adalah karena KPR dengan bank prosesnya lama dan rumit. Alasan ini dipilih oleh $24,1 \%$ responden. Sebanyak $86,2 \%$ responden yang memilih KPR tanpa bank mengaku tidak akan melakukan refinancing (pendanaan kembali) menggunakan bank. Artinya, mereka akan berusaha melunasi KPR tanpa bank ke pengembang (penjual).

Dari semua responden yang diwawancarai, sebanyak $41,4 \%$ dari mereka mengaku pernah memiliki cicilan KPR dengan bank sebelumnya dan sisanya yaitu sebanyak $58,6 \%$ belum pernah memiliki cicilan KPR. Pihak yang paling mempengaruhi para responden untuk memilih KPR Syariah tanpa bank adalah diri mereka sendiri $(55,1 \%)$. Pihak lainnya antara lain anggota keluarga $(27,6 \%)$, iklan $(6,9 \%)$, sahabat $(6,9 \%)$ dan developer perumahan $(3,4 \%)$.

Informasi mengenai KPR syariah tanpa bank yang diterima para responden berasal terutama dari sahabat dan keluarga $(41,4 \%)$. Ini artinya bahwa faktor referal menjadi sangat penting dalam memasarkan perumahan syariah tanpa bank. Sumber informasi berikutnya yaitu internet/WhatsApp group/BBM group (20,7\%). Hal ini seiring dengan teknologi informasi yang berkembang sangat pesat seperti sekarang ini. Maka informasi KPR syariah tanpa bank pun menyebar cukup luas di kalangan masyarakat. Ketika ditanyai apakah para responden 


\section{Jurnal Manajemen Teori dan Terapan \\ Tahun 10. No. 3, Desember 2017}

akan merekomendasikan teman atau keluarga untuk menggunakan KPR Syariah tanpa bank, mayoritas $(89,7 \%)$ responden menjawab 'ya'.

\section{Tantangan KPR Syariah Tanpa Bank}

Dari hasil wawancara dengan para responden, diketahui bahwa terdapat beberapa tantangan yang dihadapi pengembang dan pengguna praktik KPR syariah tanpa bank agar dapat berkembang di masa yang akan datang. Tantangan pertama adalah besarnya DP (down payment) dan cicilan per bulan yang harus dibayar oleh konsumen karena tenor pembayaran kredit memang singkat, biasanya periode cicilan adalah tiga hingga lima tahun. Dua hal ini tentu cukup menyulitkan masyarakat berpenghasilan rendah. Selain itu, hal ini dapat membuat para developer cukup susah bersaing dengan KPR yang menggunakan perbankan karena KPR syariah tanpa bank terlihat lebih mahal.

Tantangan kedua adalah akad atau kontrak yang harus selalu dijaga agar tetap sesuai syariah. Para konsumen KPR syariah tanpa bank memilih praktik ini karena mayoritas mereka beranggapan bahwa KPR di bank syariah masih belum sesuai syariah atau masih bersifat riba. Pernyataan masih ribanya KPR di bank syariah muncul karena ada perbedaan pemahaman di masyarakat. Perbedaan pendapat terjadi dalam syariah karena sebagian ulama tertentu memiliki pemahaman berbeda atas suatu hukum atau kebijakan terutama yang tidak dinyatakan secara eksplisit dalam sumber hukum utama yaitu Quran dan hadist (Zaidi, Shah, Ashraf, Ghauri, \& Hassan, 2015).

Tantangan ketiga adalah pelayanan (services) dari pengembang. Para konsumen KPR syariah tanpa bank mengharapkan pelayanan yang profesional sebagaimana pelayanan yang diberikan oleh perbankan pada umumnya. Beberapa aspek yang penting dalam pelayanan adalah tingkat kecepatan proses dalam pecah tanah, kejelasan informasi cicilan serta SDM developer yang berorientasi pada pelanggan (customer oriented).

Tantangan keempat adalah minimnya iklan dan sosialisasi praktik KPR syariah tanpa bank. Kurang sosialiasi dan edukasi menyebabkan praktik ini masih sangat terbatas di kalangankalangan tertentu. Untuk mengembangkan praktik ini, maka developer perlu lebih giat melakukan marketing sehingga semakin banyak orang yang mengetahui praktik ini.

\section{SIMPULAN}

Praktik KPR syariah tanpa bank merupakan alternatif yang dapat dipilih para konsumen yang hendak membeli rumah dan mementingkan aspek kepatuhan pada syariah. Berdasarkan penelitian yang kami lakukan, mayoritas respoden yang masuk ke dalam kategori ini adalah para keluarga muda berpenghasilan menengah ke atas dan memiliki latar pendidikan yang baik. Mereka beranggapan bahwa praktik KPR di bank syariah masih tergolong riba sehingga praktik KPR syariah tanpa bank adalah solusi agar terhindar dari riba.

Perbankan syariah kini menghadapi pesaing baru yaitu para developer properti syariah. Jika dulu developer menggunakan pihak perbankan, maka kini mereka dapat langsung menjual rumah ke tangan konsumen. Dengan demikian, perbankan syariah tentu harus serius melihat hal ini karena ceruk pasar KPR syariah semakin terfragmentasi. Jika skala KPR syariah ini semakin besar, maka bukan tidak mungkin KPR syariah di perbankan syariah kedepannya akan mengalami penurunan omzet.

Penelitian ini terbatas di beberapa kota dan kabupaten di provinsi Jawa Barat dan jumlah sampel yang digunakan relatif sedikit yaitu 29 responden karena banyak responden yang 
tidak bersedia diwawancarai serta kurang kooperatifnya para developer KPR syariah tanpa bank dalam memberikan data para konsumennya. Penelitian selanjutkan dapat memperluas area penelitian yaitu di seluruh Indonesia sehingga jumlah sampel penelitian dapat lebih banyak.

\section{Daftar Pustaka}

Amin, H., Rahman, A. R. A., Razak, D. A., \& Rizal, H. (2017). Consumer attitude and preference in the Islamic mortgage sector: a study of Malaysian consumers. Management Research Review, 40(1), 95-115. http://doi.org/http://dx.doi.org/10.1108/MRR-09-2015-0216

Bellalah, M., Rehman, A. A., \& Masood, O. (2013). Syariah Compliant Screening Practices. Thema Working Paper n²013-16 Université de Cergy Pontoise, France.

Firmansyah, E. A. (2016). Non-Bank Approach in Islamic Mortgage: The Evidence from Indonesia. In The 4th WAIBS Conference (pp. 1-7). Bandung.

Hamid, A., \& Masood, O. (2011). Selection criteria for Islamic home financing: a case study of Pakistan. Qualitative Research in Financial Markets, 3(2), 117-130. http://doi.org/10.1108/175541711111155357

Smolo, E., \& Hassan, M. K. (2011). The potentials of Musharakah Mutanaqisah for Islamic housing finance. International Journal of Islamic and Middle Eastern Finance and Management, 4(3), 237-258. http://doi.org/10.1108/17538391111144515

Wulandari, P., Putri, N. I. S. P., Kassim, S., \& Sulung, L. A. (2016). Contract Agreement Model for Murabahah Financing in Indonesia Islamic Banking. International Journal of Islamic and Middle Eastern Finance and Management, 9(2). http://doi.org/http://dx.doi.org/10.1108/IMEFM-01-2015-0001

Yusof, R. M., Bahlous, M., \& Haniffa, R. (2016). Rental rate as an alternative pricing for Islamic home financing: an empirical investigation on the UK Market. International Journal of Housing Markets and Analysis, 35, 317-360. http://doi.org/http://dx.doi.org/10.1 108/MRR09-2015-0216

Zaidi, S. A. H., Shah, I. H., Ashraf, R. U., Ghauri, S. M. K., \& Hassan, I. (2015). Standardization of Islamic market indices Syed. Emerald Insight International Journal of Commerce and Management, 33(5), 883-895. http://doi.org/10.1108/EL-01-2014-0022 